\title{
Performance Evaluation of a Parabolic Solar Dish Cooker in Yola, Nigeria
}

\author{
J. Aidan \\ Department of Physics, Modibbo Adama University of Technology, Yola, Nigeria
}

\begin{abstract}
A suitable solar parabolic dish collector cooker has been constructed and evaluated under Yola climatic conditions using the international standard procedures for the evaluation of solar parabolic cookers. The optical efficeincy of the collector has been found to be about $17.86 \%$, the overall heat loss coefficent of $8.896 \mathrm{WK}^{-1} \mathrm{~m}^{-2}$ and the adjusted cooking power that measures its performance has been found to be $96.53 \mathrm{~W}$. The parabolic solar dish collector cooker can be used by families for cooking in Yola to minimize the purchase of other cooking fuels for at least cooking the afternoon meals.
\end{abstract}

Keywords: Cooking power, optical efficiency, parabolic cooker, solar radiation

\section{Introduction}

Pollution from fossil fuels and firewood can only be minimized if majority of the populace use cleaner and environmentally friendly sources of energy like solar and wind. Parabolic solar dish cooker, because of its ability to capture enough solar radiation would be suitable for this purpose. It is easy to own one, perhaps from a disposed parabolic dish of a satellite TV receiver. The parabolic solar dish cooker is generally capable of attaining higher temperatures than other solar cooking devices; in some cases, depending on the type of reflector used, it can achieve higher temperatures in excess of $1500^{\circ} \mathrm{C}$ [1].

In these periods of scarcity of cooking fuel and price inflation, a parabolic solar dish cooker would be of great economic help for the family. It will not only reduce the burden of firewood searching, but also provides cleaner and healthy way of cooking food for the family. Though, solar cooking may take longer time if there are fogs, cloud or shadow, it is still the best cooking device that is needed to be considered. The most interesting thing about cooking with the sun is that your food will never get burnt no matter how long it is allowed to cook.

In Nigeria, many designs and constructions of solar parabolic dish collectors have been done [2\&3]. However most of the authors used other testing procedures which may be different from the international standard procedure developed [4\&5] for the evaluation of solar parabolic dish cookers. Therefore, one may not be sure if their effective cooking powers were correctly estimated under such climatic conditions. Moreover none of these evaluations have been done in Yola. Yola is located at latitude $9.23^{\circ} \mathrm{N}$ and longitude $12.47^{\circ} \mathrm{E}$; it has abundance of sunshine and may be suitable for solar thermal applications like solar parabolic dish cookers. In this work, a solar parabolic dish collector cooker has been constructed and evaluated using the international standard procedures.

\section{Theory and Methods}

2.1 Theory of parabolic dish solar collector

The parabolic solar collector makes use of the direct solar radiation for heating at its focus. The measure of the concentration of the radiation flux is described in terms of the optical concentration $\mathrm{C}_{\mathrm{o}}$ given by:

$$
C_{o}=\frac{I_{r}}{I_{o}}
$$

where ${ }^{I}$ solar intensity at the receiver and ${ }^{{ }^{\circ}}{ }_{\text {is }}$ the solar intensity at the collector.

Concentration ratio can also be determined in terms of the aperture aerial dimension of the parabolic collector $A_{p}$ and the receiver surface area $A_{t}$; it is usually referred to as the geometric concentration ratio $\mathrm{C}$ given by:

$$
C=\frac{A_{p}}{A_{t}}
$$

The focal height ${ }^{f}$ with respect to the vertex of the solar parabolic dish collector, the height of the dish ${ }^{h}$ and the diameter of the dish ${ }^{R}$ are related by: 


$$
h=\frac{R^{2}}{16 f}
$$

\subsection{The constructed parabolic solar dish cooker}

The solar parabolic dish collector is made from a $0.7 \mathrm{~mm}$ thick Aluminum sheet to reduce heat loss. Iron bars were used to create supports for the dish and the pot. A manual sun tracking mechanism made of iron bars was also incorporated to constantly adjust the cooker to the sun's direction. Thin linings of Aluminum foil paper were used as the reflector on the outer surfaces of the dish. A matt black painted cylindrical pot of diameter $0.215 \mathrm{~m}$ and height $0.15 \mathrm{~m}$ was used as the receiver/absorber (cooking utensil) for the experimental evaluation of the solar parabolic dish collector. Fig. 1 gives the schematic diagram highlighting the parameter symbols and definitions alongside the constructed parabolic solar dish collector. Table 1 gives the parameters of the constructed parabolic solar cooker and the utensil.
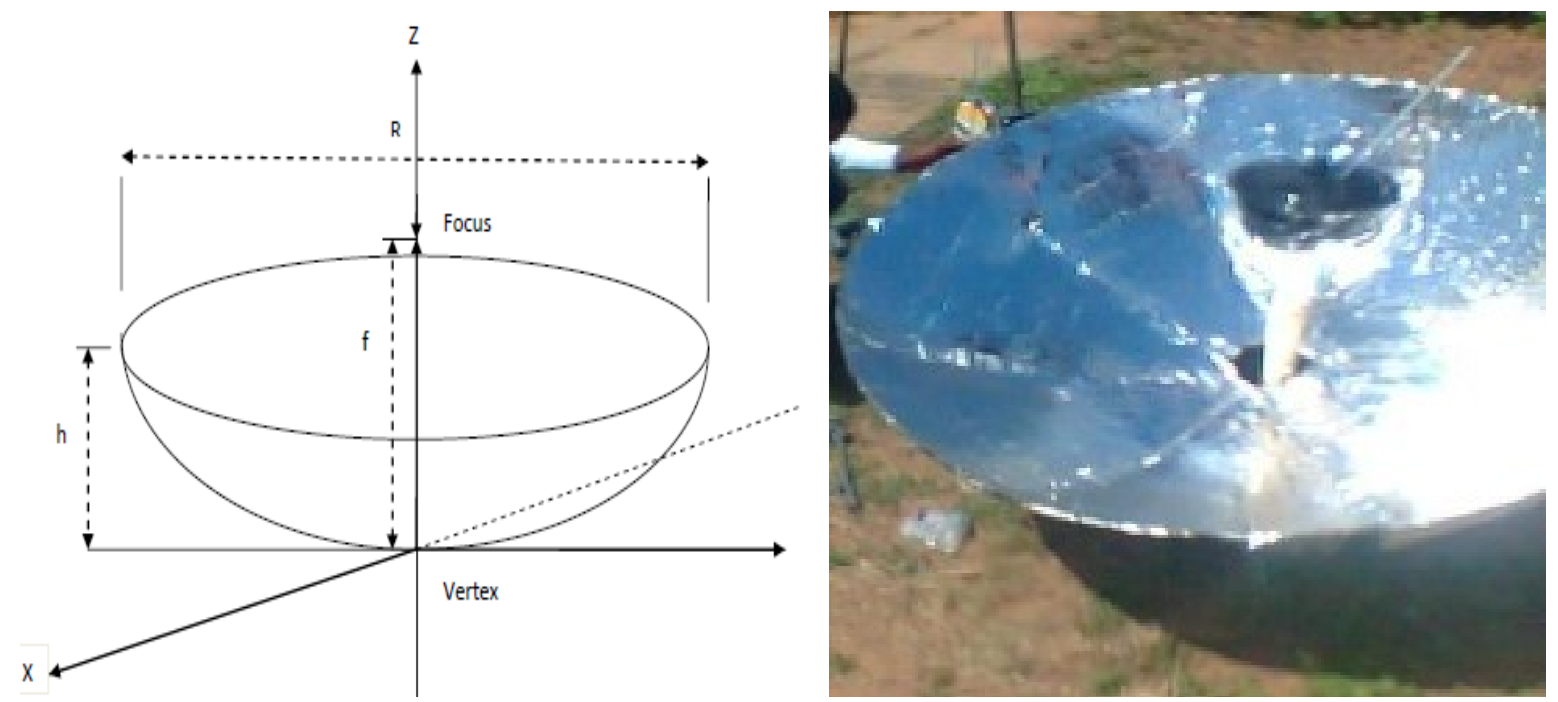

Figure 1: Schematic and the constructed views of the solar parabolic dish collector cooker

Table 1: Parabolic Dish Cooker and Receiver Parameters

\begin{tabular}{cccccc}
\hline $\mathrm{R}$ & $\mathrm{f}$ & $\mathrm{h}$ & $\mathrm{A}_{\mathrm{p}}$ & $\mathrm{A}_{\mathrm{t}}$ & $\mathrm{C}$ \\
$(\mathrm{m})$ & $(\mathrm{m})$ & $(\mathrm{m})$ & $\left(\mathrm{m}^{2}\right)$ & 0.138 & 8.896 \\
\hline 1.25 & 0.42 & 0.23 & 1.228 & 0.138 \\
\hline
\end{tabular}

\subsection{Testing of the solar parabolic cooker}

With the parabolic solar cooker placed under the sun, a $0.40 \mathrm{~kg}$ mass of cooking pot containing $0.37 \mathrm{~kg}$ of water was placed at the focus of the dish which already has been oriented in the direction of the sun. The temperatures at intervals of 5 minutes were measured with a thermometer until the water started boiling. The readings for this part of the experiment were recorded and used for the heating test analysis. At the time the water had started boiling, the set-ups were immediately shaded for the cooling test. As the temperature of the water contained in the cooking pot falls, a record of the temperature were taken at an interval of 4 minutes until the temperature of the water approaches that of the ambient.

The cooling and heating tests as suggested [5] were used to determine the heat loss factor $F^{\prime} U_{L}$ and the optical efficiency factor, $F^{\prime} \eta_{0}$ :

$$
F^{\prime} U_{L}=\frac{(M C)_{w}^{\prime}}{\tau_{o} A_{t}}
$$

where $\tau_{o}$ is the time constant determined as the temperature difference $\left({ }^{T_{w}}-T_{a}\right)$ falls to $1 / \mathrm{e}$ of its initial value and $A_{t}$ is the surface area of the cooking utensil. $(M C)_{w}^{\prime}$ is the combined heat capacities of water and the cooking utensil which is equivalent to:

$$
(M C)_{w}^{\prime}=M_{w} c_{w}+M_{p} c_{p}
$$


where ${ }^{M_{w}}$ is the mass of water, ${ }^{c_{w}}$ is the specific heat capacity of water $\left(=4190 \mathrm{Jkg}^{-1} \mathrm{~K}^{-1}\right),{ }^{M_{p}}$ is the mass of pot and ${ }^{c_{p}}$ is the specific heat capacity of the pot. Since the pot is made of Aluminum implies that ${ }^{c_{p}}$ is the specific heat capacity of Aluminum.

The optical efficiency factor for the solar parabolic collector can be determined from:

$$
F^{\prime} \eta_{0}=\frac{F^{\prime} U_{L}}{C} \frac{\left\{\left(\frac{T_{w f}-\bar{T}_{a}}{\bar{I}_{b}}\right)-\left(\frac{T_{w i}-\bar{T}_{a}}{\bar{I}_{b}}\right) e^{-\tau / \tau_{0}}\right\}}{1-e^{-\tau / \tau_{o}}}
$$

where $T_{w i}$ and $T_{w f}$ are the initial and final water temperatures during the heating test respectively, ${ }^{\tau}$ the time required for the water temperature to increase from $T_{w i}$ to $T_{w f}, \bar{T}_{a}$ is the average ambient temperature, and $\bar{I}_{b}$ is the direct solar radiation during time interval $\tau$.

Other test techniques as suggested [6] were also used to evaluate the parabolic solar dish collector. In these techniques, the cooking power, standardized cooking power and the overall heat loss coefficient were determined subject to the conditions that the wind speed not been greater than $2.5 \mathrm{~m} / \mathrm{s}$, air temperature in the range of 20 to $35^{\circ} \mathrm{C}$ and radiation range of $450 \mathrm{Wm}^{-2}$ to $1100 \mathrm{Wm}^{-2}$. With the variations shown in Fig 2 (a \& b) and an average beam insolation of $608 \mathrm{Wm}^{-2}$ the required conditions were duly satisfied.

The average values of environmental condition parameters are presented in Table 2 and their variations with the local time of the day of experiment were presented in Figure $2(a \& b)$

Table 2: Average Values of the Wind Speed, Ambient Temperature, Insolation with the Initial and Final Water Temperatures during the Heating Test

\begin{tabular}{ccccc}
\multicolumn{4}{c}{ Initial and Final Water Temperatures during the Heating Test } \\
\hline $\begin{array}{c}\text { Wind speed } \\
\left(\mathrm{ms}^{-1}\right)\end{array}$ & $\begin{array}{c}\bar{T}_{a} \\
\left({ }^{\circ} \mathrm{C}\right)\end{array}$ & $\begin{array}{c}\bar{I}_{b} \\
\left(\mathrm{Wm}^{-2}\right)\end{array}$ & $\begin{array}{c}T_{w i} \\
\left({ }^{\circ} \mathrm{C}\right)\end{array}$ & $\begin{array}{c}T_{w f} \\
\left({ }^{\circ} \mathrm{C}\right)\end{array}$ \\
\hline 1.52 & 31.88 & 608 & 60 & 95 \\
\hline
\end{tabular}

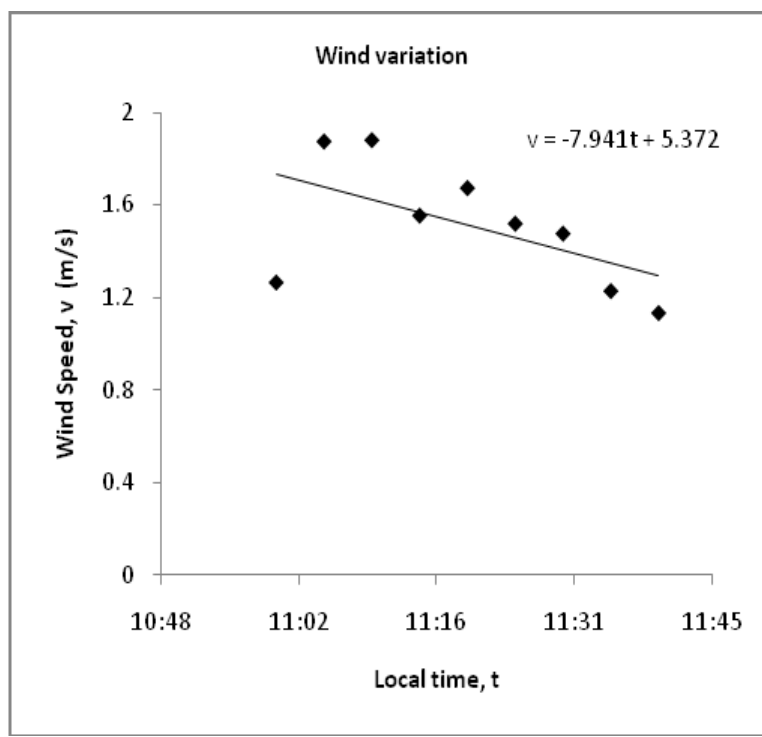

(a)

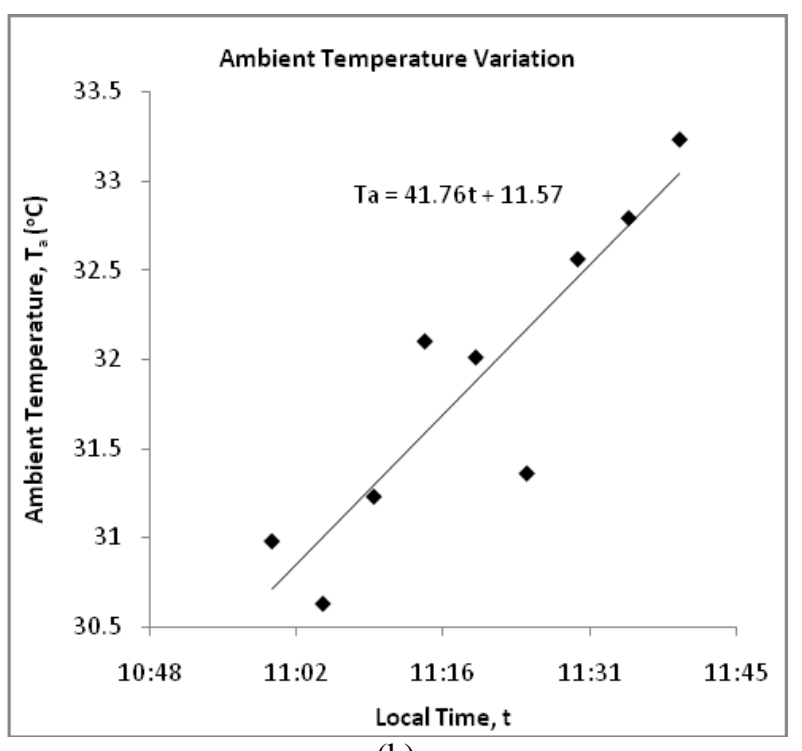

(b)

Figure 2: Wind speed (a) and ambient temperature (b) variation with local time on the day of experiment The cooking power $\mathrm{P}$ of the parabolic solar cooker which is the rate of useful energy available during heating period is given as:

$$
P=M_{w} c_{w} \frac{\left(T_{w b}-T_{w a}\right)}{\tau}
$$

$\mathrm{P}$ at each interval is corrected to a standard irradiance of $700 \mathrm{Wm}^{-2}$ using:

$$
P_{s}=M_{w} c_{w} \frac{\left(T_{w b}-T_{w a}\right) \times 700}{\tau I_{b}}
$$

The overall heat loss coefficient $U_{L}$ is determined from the plot of $P_{s}$ against $\left(T_{w}-T_{a}\right)$ such that 


$$
U_{L}=\frac{\text { slope }}{A_{t}}
$$

\section{Results and Discussion}

Fig 3(a) presents the plots for the heating test of the variation of the water temperatures against the local time of the day. The graph shows how the temperature of the water increases with respect to the amount of solar insolation (Fig 3b) received by the absorber over the experimental period from the dish surface. The variation is seen not to be completely linear as water approaches it boiling point. The non-linearity of the temperature of the water can be attributed to the losses that came from interaction of the absorber with the environment.

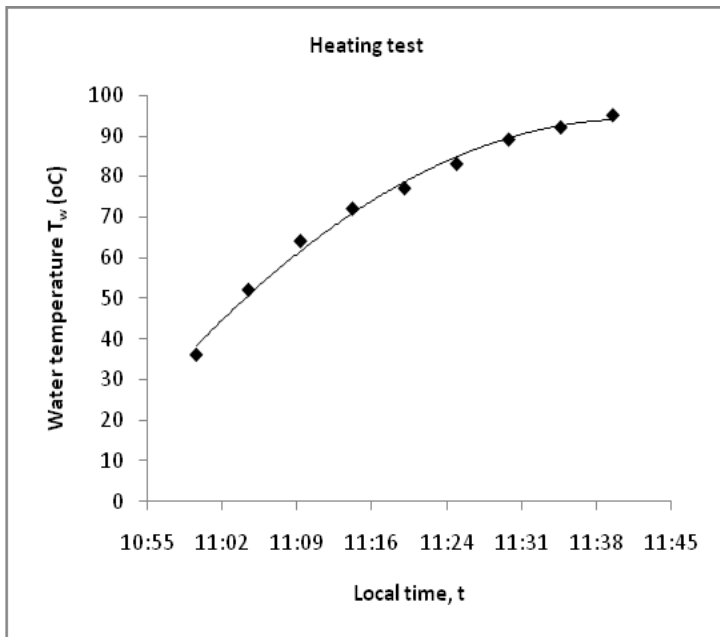

(a)

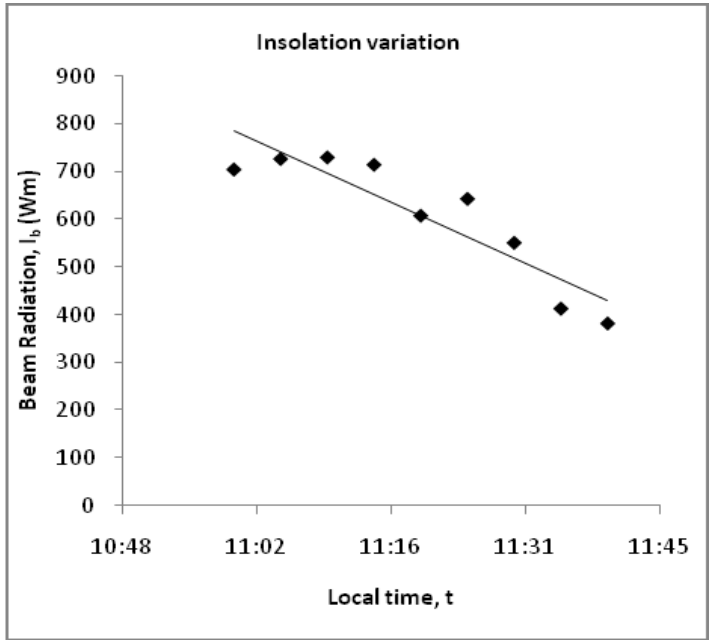

(b)

Figure 3: Graphs of water temperature (a) and global insolation (b) against local time

For the heating test procedure, the heating time $\tau$ for the water temperature to inrease from the initial temperature of $60^{\circ} \mathrm{C}$ to $95^{\circ} \mathrm{C}$ was determined and consequently using the values presented in Table 2, the optical efficiency factor $F^{\prime} \eta_{o_{0}}$ of the collector was also evaluated from equation (7) with the heat loss factor $F^{\prime} U_{L}$ determined from equations $(5 \& 6)$. These values are presented in Table 3 . Also presented are the determined values of $\tau_{0}$ from Fig. $4 \mathrm{a}$, the optical efficiency $\eta_{o}$ and the adjusted cooking power $\mathrm{P}_{\mathrm{a}}$ of the solar parabolic dish cooker determined from Fig. $4 \mathrm{~b}$.

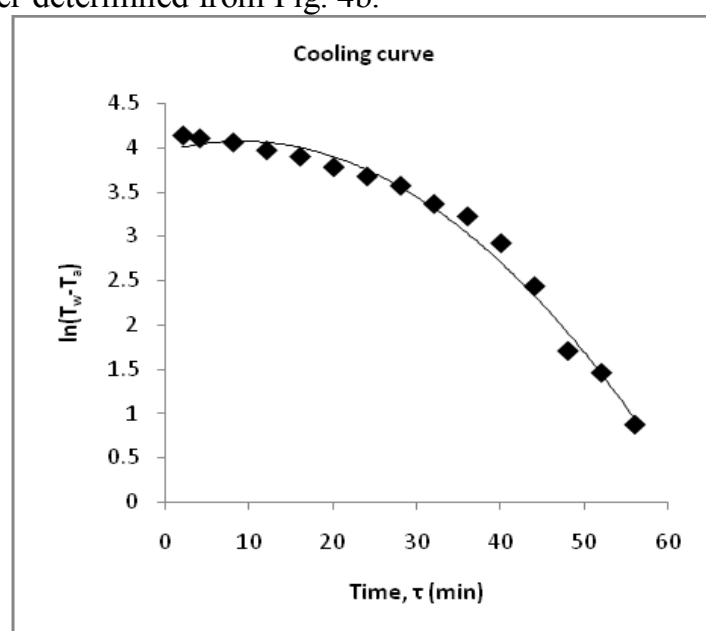

(a)

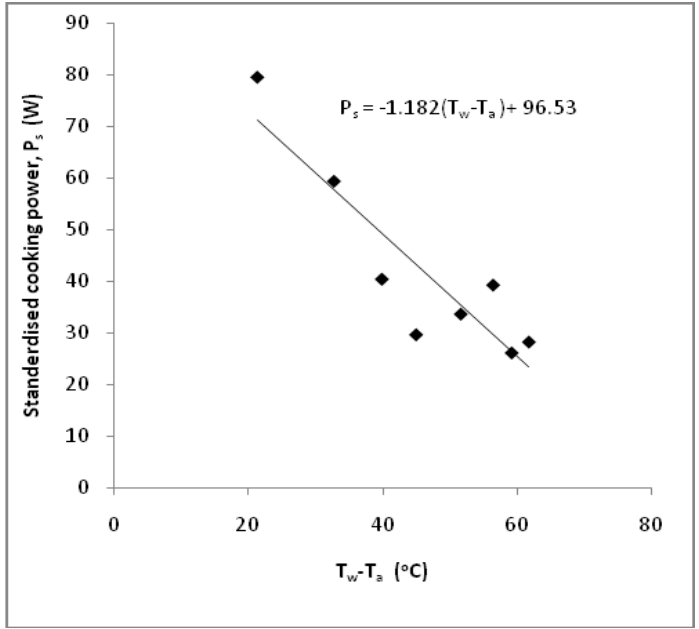

(b)

Figure 4: cooling curve (a) and a plot of standardised cooking power against difference in temperature (b) 
Table 3: Solar Parabolic Dish Collector Cooker Performance Results

\begin{tabular}{|c|c|c|c|c|c|c|c|c|}
\hline $\begin{array}{c}(M C)_{w}^{\prime} \\
\left(\mathrm{JK}^{-1}\right)\end{array}$ & $\begin{array}{c}\tau_{o} \\
(\mathrm{~s})\end{array}$ & $\begin{array}{c}\tau \\
(\mathrm{s})\end{array}$ & $F^{\prime} U_{L}$ & $F^{\prime} \eta_{o}$ & $\begin{array}{c}U_{L} \\
\left(\mathrm{WK}^{-1} \mathrm{~m}^{-2}\right)\end{array}$ & $F^{\prime}$ & $\begin{array}{c}\eta_{o} \\
(\%)\end{array}$ & $\begin{array}{c}\mathrm{P}_{\mathrm{a}} \\
(\mathrm{W})\end{array}$ \\
\hline 1914.3 & 3150 & 1680 & 4.404 & 0.0918 & 8.565 & 0.514 & 17.86 & 96.53 \\
\hline
\end{tabular}

From the results in Table 3, an optical efficiency of $17.86 \%$ was determined for the parabolic dish collector; the low value could be that the aluminum foil were not laid smoothly on the collector surface to offer a regular reflection on to the cooking utensil hence resulted into considerable radiation loss to the environment. Other losses represented by the overall heat loss coefficient of $8.656 \mathrm{WK}^{-1} \mathrm{~m}^{-2}$ from all the surfaces of the cooking utensil itself to the environment. The adjusted cooking power of $96.53 \mathrm{~W}$ gave the measure of the performance of the solar parabolic dish cooker. This value has shown that the cooker had offered $96.53 \mathrm{~J}$ of heat energy onto the water contained in the cooking utensil every second. That is, for the heating duration of 28 minutes $\left(1680 \mathrm{~s}\right.$ ) between $60^{\circ} \mathrm{C}$ and $95^{\circ} \mathrm{C}$ the water had received about $162120 \mathrm{~J}$ of heat energy.

\section{Conclusion}

It is possible to use solar parabolic dish collector as cooker to complement other conventional cooking devices in Yola especially between 11:00 am and 3:00 pm when the solar radiation are considered higher. The fact that solar energy is free, the low optical efficiency of the collector is immaterial as long as clean cooking is done and the good health of the users are preserved.

\section{References}

[1]. S. A. kalogirou, Solar thermal collectors and applications, Progress in Energy and Combustion Science, 30, $2004,231-295$.

[2]. I. L Mohammed, Design and development of a parabolic solar thermal cooker, International Journal of Engineering Research and Applications, 3(4), 2013, 1179-1186.

[3]. J. Folaranmi, Design, construction and testing of a parabolic solar steam generator, Leonardo Electronic Journal of Practices and Technologies, 14, 2009, 115-133.

[4]. A. P. Funk, Evaluating the international standard procedure for testing solar cookers and reporting performance, Solar Energy, $68(1), 2000,1-7$

[5]. S. C. Mullick, T. C. Kandpal and S. Kumar, Thermal test procedure for a paraboloid concentrator solar cooker, Solar Energy, 46, $1991,139-144$. 